\title{
DESIGN AND IMPLEMENTATION OF DYNAMIC KNOWLEDGE MODEL FOR SUITABLE VARIETY SELECTION AND SOWING TIME DETERMINATION OF SOYBEAN
}

Xiangliang $\mathrm{Wu}^{1,2}$, Julin Gao ${ }^{1, *}$, Yvdong Zhao ${ }^{2}$, Lijun $\mathrm{Li}^{1}$, Man $\mathrm{Li}^{1}$, Zhigang Wang ${ }^{1}$

${ }^{I}$ Agricultural institute of Inner Mongolian Agriculture University, huhhot 010010, China;

${ }^{2}$ Inner Mongolian animal husbandry hall information center;

* Corresponding author, Address: Gao Julin(1964-),male, professor, tutor of doctoral candidates, agricultural college of inner Mongolia university, direction of study:crop optimizing cultivation an decision system, E_mail:gaojulin@yahoo.com.cn

Abstract: $\quad$ Using knowledge engineering principle and mathematical modeling technique, the model was established, it was the dynamic knowledge model of suiting soybean varieties, variety selection and variety sowing time determination through aggregating the results of existing research and analysising Experimental data. the knowledge model was verified through six different ecological points of Inner Mongolia and different varieties data. The results show that the model has a better decision-making and universal application.

Keywords: soybean, model, expert system, variety selection, sowing time

\section{INTRODUCTION}

Soybean variety selection is the guarantee of obtaining high quality and high yield. It is mainly through variety introduction test and experience of expert in production, it lacks quantitative indicators and increases the variety updating time. The study determines the suitability, variety selection and

Please use the following format when citing this chapter:

Wu, X., Gao, J., Zhao, Y., Li, L., Li, M. and Wang, Z., 2009, in IFIP International Federation for Information Processing, Volume 294, Computer and Computing Technologies in Agriculture II, Volume 2, eds. D. Li, Z. Chunjiang, (Boston: Springer), pp. 847-852. 
variety sowing time determination of soybean,the result of study guides soybean production.

\section{MATERIALS AND METHODS}

Looking up a large number of documents and consulting the expert of soybean cultivation, these are the basis.determine.then thinking the relationship between characteristics of variety kinds and ecological environment, in the end ,the model is established through the summary, inducing and refining the study data of the soybean cultivation principles and technology. Further do mathematical statistical analysis on the basis of obtaining test data and transform the collected conceptual model to quantitative mathematical model which can solve problem.

\section{MODEL DESIGN}

\subsection{The model of soybean suitability}

The suitability of soybean is the primary considered problem in plan design before planting. It is on the basis of the perennial weather condition ( $\geq 10{ }^{\circ} \mathrm{C}$ active accumulated temperature) of the decision point, such as light and water and so on.

The effective accumulated temperature can show temperature condition of the local growing season. It determines the suitability of planting soybean Considering the local precipitation and irrigation.

Whether the decision point can plant soybean or not can be described quantitatively by equation (1). SGP means the possibility of soybean planting. When SGP is equal to one, it means that it can plant soybean ,but when SGP is equal to zero, it means the field can't plant soybean. JW、JS、 GS $、 \mathrm{KH}$ respectively means the active accumulated temperature that is higher than ten centigrade, annual rainfall $(\mathrm{mm})$, whether have irrigation condition or not(1 means have irrigation condition) and whether select drought-resistant varieties or not.

$$
\mathrm{SGP}= \begin{cases}1 & \mathrm{JW} \geq 1900 \quad \text { and } \quad \mathrm{JS} \geq 400 \\ 1 & \mathrm{JW} \geq 1900 \quad \text { and } \quad 400 \geq \mathrm{JS} \geq 350 \quad \text { and } \mathrm{KH}=1 \\ 1 & \mathrm{JW} \geq 1900 \quad \text { and } \quad \mathrm{JS} \leq 350 \quad \text { and } \quad \mathrm{GS}=1 \\ 0 & \text { Non }- \text { coincidenc } \quad \text { e above }\end{cases}
$$


Temperature directly impact on the whole growth process of soybean which is from emergence, flowering to maturity. When the activities temperature that is higher than ten centigrade is lower than 1900 centigrade, the soybean will be difficult to be mature or instable of production. The study shows that when the soybean yield is higher $2625 \mathrm{~kg} \cdot \mathrm{hm}-2$, the water requirement is more than $400 \mathrm{~mm}$. The system regulates(Mao Hongxia et al.2007,Li Yunge et al.2001, Xu Shuqin et al.2001) that when the precipitation of growth period is between $350 \mathrm{~mm}$ and $400 \mathrm{~mm}$, it need to choose drought-resistant variety under non-irrigation condition. The variety drought-resistant evaluation can be seen in the table six. When the precipitation is less than $350 \mathrm{~mm}$ in the growth period, the field can't plant soybean under non-irrigation condition.

\subsection{The model of soybean variety selection}

Yield is the most concerned problem by user. The soybean variety selection can be described quantitatively by equation (2). It usually needs that the confidence degree of yield is more than 80 percent.

$$
\mathrm{ZXD}= \begin{cases}\mathrm{PY} / \mathrm{STY} & \mathrm{PY}<\mathrm{STY} \text { and } \mathrm{SYQ} \leq \mathrm{WSQ}-12 \\ 1.0 & \mathrm{PY} \geq \mathrm{STY} \text { and } \mathrm{SYQ} \leq \mathrm{WSQ}-12\end{cases}
$$

ZXD、PY、SYT respectively means confidence degree of variety need, yield potential of variety and target yield. When the confidence is more than 80 percent, it will be possible to be chosen. SYQ is the growth period of variety and WSQ is the frost-free period of decision point.

Spring soybean is mainly cultivated in the north of China. Selection of longer growth period variety will obtain high yield easily but also be threated by early frost. Central Meteorological Station regulations show that an early frost ahead of six days is normal, but ahead of seven to eleven days it is partial early. When ahead of more than twelve days, it is special early frost, etc have analyzed the earliest frost of the northeastern region between 1967 and 1997(Yang Keming et al.1999). The result shows that early frost in extremely early years is nineteen percent and is twenty-nine percent in partial early years. Partial and normal year is about respectively half each other.

Therefore, in order to use the regional yield-increasing potential and reduce the influence of frost, the model requires that the frost-free period of decision point should be twelve days more than the selected variety.

Confidence degree is the credibility of chosing result by system and can be expressed by equation (3).

$$
\mathrm{ZXD}=1-\prod_{\mathrm{i}=1}^{\mathrm{N}} \frac{\left|\mathrm{X}_{\mathrm{iy}}-\mathrm{X}_{\mathrm{ix}}\right|}{\mathrm{X}_{\mathrm{ix}}}
$$


ZXD is the confidence degree, Xix and Xiy mean the predicted value and actual value of some indictor of model in turn.

\subsection{Model of soybean sowing time}

Not only Soybean sowing time have direct effect on growth and development, but also maturity and yield have significantly effect to the quality of soybean(Han TianFu,2004). In general, oil content of spring sowing soybean is higher than the summer sowing and the summer sowing soybeans is higher than the autumn sowing(Ren XiuRong et al.2005, Xu HaiTao et al.2007). The trend of the protein content is opposite. Therefore, the proper sowing time benefit to improve the yield and quality of high oil soybean.

When the average soil temperature from $0 \mathrm{~cm}$ to $5 \mathrm{~cm}$ passes the temperature of from $8{ }^{\circ} \mathrm{C}$ to $10^{\circ} \mathrm{C}$ stably the soybean can be sowed. The system identify $\mathrm{T}$ as $10^{\circ} \mathrm{C}$. when under film-covering condition identify $\mathrm{T}$ as $8{ }^{\circ} \mathrm{C}$ (Zhou Baoku et al.2004).Despite existing regional inter-annual temperature difference, it is stable in general. The system is used to predict the future years' climate situation by perennial climate. The identification of perennial climate can refer to the method of Gao Liangzhi. According to the years' average value input by user and included month average temperature, month average highest and lowest temperature and month sunshine hours, use harmonic analysis and generate daily climate data(average temperature, the maximum, Low, etc.) automatically. Use the equation (4) during the process of sowing time identification:

$$
\text { Tdi } \geq \mathrm{T} \quad(\mathrm{i}=1,2,3,4,5)
$$

Tdi means continuous few days average temperature of decision place, $\mathrm{T}$ means the suitable temperature for sowing. $\mathrm{d} 1-\mathrm{d} 5$ can be as the suitable sowing time of soybean which meet the equation.

\section{MODEL TEST}

The model of suitability soybean is feasible in principle because it is the application of the integration, analysis and refining of the existing research. So the target of model test is variety selection and sowing time identification. On the basis of the situation of the decision place, requirement of user and predicted yield, select suitable variety from the varieties resources database of soybean using variety selection knowledge model and give confidence degree. Analyze the variety selection model by six different ecological sites 
of HuLunBeiEr. Table 1 shows the suitable planting variety which knowledge model select for user on the basis of their input demand.

Table 1 Variety selection determined by knowledge model for six different eco-sites during normal climatic year

\begin{tabular}{|c|c|c|c|c|c|c|}
\hline Decision site & $\begin{array}{l}\text { frost-free } \\
\text { season }\end{array}$ & $\begin{array}{l}\text { Accumulative } \\
\text { Temperatures }\left({ }^{\circ} \mathrm{C}\right)\end{array}$ & $\begin{array}{l}\text { whether or not } \\
\text { irrigating }\end{array}$ & $\begin{array}{l}\text { expected yield } \\
\left(\mathrm{kg} \cdot \mathrm{hm}^{-2}\right)\end{array}$ & $\begin{array}{l}\text { name of } \\
\text { cultivars }\end{array}$ & $\begin{array}{l}\text { confidence } \\
\text { degree }\end{array}$ \\
\hline \multirow{3}{*}{$\begin{array}{l}\text { HuLunBeiEr } \\
\text { Agricultural } \\
\text { Institute }\end{array}$} & \multirow{3}{*}{$100 \sim 112$} & \multirow{3}{*}{2380} & \multirow{3}{*}{ yes } & \multirow{3}{*}{3150} & Jiangdou 9 & 0.965 \\
\hline & & & & & Jingmodou 1 & 0.893 \\
\hline & & & & & Mengdou 12 & 0.845 \\
\hline \multirow{2}{*}{ ARong Banner } & \multirow{2}{*}{$90-120$} & \multirow{2}{*}{2150} & \multirow{2}{*}{ yes } & \multirow{2}{*}{300} & Mengdou 11 & 0.983 \\
\hline & & & & & Hefeng 40 & 0.893 \\
\hline \multirow{2}{*}{$\begin{array}{l}\text { MoLiDaWa } \\
\text { Banner }\end{array}$} & \multirow{2}{*}{$110-120$} & \multirow{2}{*}{2250} & \multirow{2}{*}{ yes } & \multirow{2}{*}{3300} & Dongnong 434 & 0.921 \\
\hline & & & & & Heihe 750 & 0.912 \\
\hline \multirow{2}{*}{ ZaLaiTe Banner } & \multirow{2}{*}{$125-135$} & \multirow{2}{*}{2760} & \multirow{2}{*}{ yes } & \multirow{2}{*}{3600} & Dongnong 434 & 0.991 \\
\hline & & & & & Dongnong 163 & 0.904 \\
\hline \multirow{2}{*}{$\begin{array}{l}\text { WengNiuTe } \\
\text { Banner }\end{array}$} & \multirow{2}{*}{$130-158$} & \multirow{2}{*}{3071.7} & \multirow{2}{*}{ no } & \multirow{2}{*}{2100} & Dongnong 9031 & 10.952 \\
\hline & & & & & Zhongzuo 983 & 0.876 \\
\hline \multirow{2}{*}{$\begin{array}{l}\text { SaiHan Urban in } \\
\text { huhhot }\end{array}$} & \multirow{2}{*}{$125-131$} & \multirow{2}{*}{2847.9} & \multirow{2}{*}{ yes } & \multirow{2}{*}{3450} & Jiyu 47 & 0.962 \\
\hline & & & & & Jiyu 56 & 0.923 \\
\hline
\end{tabular}

Simulating the main soybean planting areas of Inner Mongolia by the model of sowing time, the results are following in table 2. it shows that the model guides local soybean production.

Table2 Suitable sowing-date of soybean in inner mongolia

\begin{tabular}{lll}
\hline \multirow{2}{*}{ Area } & \multicolumn{2}{c}{ planting date } \\
\cline { 2 - 3 } & prediction & Practical(2006) \\
\hline Northern HuLuBeiEr & May 12 & May 14 \\
Southern HuLuBeiEr & May 7 & May 8 \\
XingAn,TongLiao,ChiFeng & May 3 & May 6 \\
HuHHot & April 29 & April 28 \\
\hline
\end{tabular}

\section{CONCLUSION AND DISCUSSION}

5.1 Using the knowledge engineering principles and mathematical model techniques, we have established the model of variety selection and sowing time identification, the model is refined and analyzed the soybean growing and management indictor and variety type, environmental factors between the basic relations and quantitative algorithm.

5.2 Lack of soybean grain quality quantitative description in the model and need to be modified and improved in future study. 


\section{REFERENCES}

Han TianFu. Technique guideline in Soybean's Plant of Good Quality and High Production[M].beijing: China Agricultural Science and Technology press,2005.

Li YunGe,Gao YuFeng, Chai YongZhao,etc. the modulus water requirements study of Soybean spray irrigation[J].soybean bulletin. 2001(5):8-9.

Mao HongXia,Zhang ChangFu,He LinWang. The influence of different irrigation to soybean yield and quality under spray irrigation [J]. Xinjiang Farmland Reclamation Science \& Technology. 2007(6): 35-36.

Ren XiuRong,Xu HaiTao,Wu DeKe.etc.the affect of different sowing time and climatic condition to soybean grain quality and main traits[J].soybean science. 2005(1): 71-73.

$\mathrm{Xu}$ HaiTao,Xu Bo,Wang YouHua.the affact of different sowing time and good fertilization to high oil soybean yield and quality[J].shanxi agicultural science, 2007, 35(5): 51-53.

Yang KeMing,Chen XiuFeng,Wang DongSheng,etc.the climatic characteristic of early frost of north-east region[J].meteorology. 1999(6):13-18.

Yang QingKai, Ning HaiLong,Xu YanLi,etc.the affect of successive and alternate stubble to soybean chemical quality under different ecological condition.soybean science. 2001,20 (3):187-190.

Zhou Baoku,Zhang XiLin,Huan LiHai,etc.the early study result of film corvered to soybean yield increasing.heilongjian agicultural science 2004,(3):6-8. 